\title{
Cooking behaviours: a user observation study to understand energy use and motivate savings
}

\author{
Luis Oliveira $^{\mathrm{a}, *}$, Val Mitchell ${ }^{\mathrm{a}}$ and Kevin Badni ${ }^{\mathrm{a}}$ \\ ${ }^{a}$ Loughborough Design School, Loughborough University, Loughborough, Leicestershire, LE11 3TS, United \\ Kingdom
}

\begin{abstract}
Electric cookers are one of the highest energy consuming domestic appliances, and there are several aspects that can influence the amount of energy used when preparing a meal. Appliance characteristics are shown to influence consumption, but human factors play an important role in the overall electricity usage. A user observation study was conducted among university students to understand how they use electric cookers. They were asked to perform a specific cooking task, and the electricity usage was measured. Participants' behaviours were analysed and compared with a set of energy saving techniques. Appliance characteristics that influenced how students use energy were also investigated. The results show that users performed the task in several different ways, presenting diverse energy consumption, the average being 3 times above the necessary to complete the task. This information is now informing the design of interventions to motivate people to change their behaviours whilst cooking.
\end{abstract}

Keywords: Energy saving, cookers, user observation,

\section{Introduction}

About $75 \%$ of the UK electricity is produced by thermoelectric plants [9], which are responsible for a big share of the carbon emissions. The housing sector accounts for more than one third of the energy consumption [9]. Reducing domestic energy use therefore represents a significant opportunity to reduce human impact on the environment.

Two important ways of reducing domestic energy consumption are through efficiency and curtailment. It is possible to build products that use less energy via better product design and engineering, and it is also possible to reduce the energy consumption by the way people use these products. The cooking activity demands several interactions between users and appliances, the user is next to the appliance during energy consumption, and there are numerous energy saving behaviours that can be performed during the cooking activity [21]. Consequently, people's behaviours play an important role in energy consumption.
Technological advancements allowed appliances to become highly efficient. For example, refrigerator and freezer improvements meant that the European Union Energy Label system have had to create three additional classes $(\mathrm{A}+, \mathrm{A}++$, and $\mathrm{A}+++)$ to the original classification to follow the technological progress [10]. However, efficient appliances do not necessarily mean that people will use less energy. Even when living in low energy houses, inhabitants can behave in a non-efficient way [6].

In certain contexts people cannot choose the appliances they use. That is the case with tenants living in furnished houses or students living in halls of residence who seldom select the equipment to be installed. Renters often have to use appliances that are not very energy efficient [8]. Most of the self-catered student accommodations on Loughborough University campus, where this research took place, are fitted with robust cookers that are rated B by the EU Energy Label. The challenge is to make people reduce the expenditure whilst using the hardware actually

\footnotetext{
*E-mail: 1.oliveira@1boro.ac.uk. Phone: +44 (0)1509 223585, Fax: +44 (0)1509 226900
} 
available for them. This research is trying to reduce energy use for existing appliances solely through behaviour change.

There are several studies in the literature reporting attempts to modify peoples' behaviours regarding energy use. Two extensive reviews [1,19] recommend that a wider understanding is necessary in order to design effective interventions. It is crucial to identify and deeply comprehend the behaviours that need to be changed and its correspondent determinants to increase the chances of success in energy savings. Previous studies, targeting university students, achieved a relative success by offering feedback on energy use, information and financial incentives, but did not report if they investigated how energy was being used prior to the development of the interventions $[3,11,16]$.

The literature provides different examples of methods to cook more efficiently. Wood and Newborough [21] list energy saving behaviours that people can perform at home, and each of them can be applied to the use of electric hobs: manually turn the appliance on and off at the right time, select a low power input to reduce the rate of energy consumption, reduce the length of the period of use, match sizes, volumes and amount of heat to the food that needs to be prepared, choose an appliance which consumes less energy, or use a non-energy-consuming device or method. One study proved that energy management can reduce the consumption drastically for cooking rice [7]. They performed several experiments to measure and compare the differences between normal and controlled cooking. They provided the exact amount of energy needed by turning the heat off as soon as the water started to boil, and showed that it was possible to reduce the electrical energy consumption by approximately $56 \%$ compared to normal cooking. This information, allied with further literature [for example 14,20], a pilot study and in-site experiments contributed to the development of the energy saving recommendations used during this study. Therefore the aim of this study was to understand how people normally cook, their actual energy usage, how it relates to the recommended cooking behaviours and to inform the subsequent phases of this research. This data provided a wide knowledge that is now being used to develop a suitable intervention to motivate behaviour change.

\section{Methods}

To understand what are the key energy related behaviours, a user observation study was designed. Standard user observation methods $[12,18]$ guided the design of this experiment. The trials included video recording and note taking. This approach was chosen due to the complexity of behaviours, the great number of details to take note, the automation that some well-practiced behaviours present, and the subtle aspects that could end up unnoticed without video recording. The sample for this study comprised 20 subjects, 10 male and 10 female, between 18-22 years old, all British undergraduate students. They all lived in the same hall of residence and cooked a meal at least twice a week, which guaranteed that they were familiar with the specific appliances used during the trial. A regular kitchen in their hall was used for this experiment, and fitted with domestic energy monitors for the cooker and kettle. The energy monitor screen was kept out of sight during the trial, so as not to influence participants' behaviour. A rather simple cooking task was presented to the participants in order to examine how they cook and how they use energy. They were asked to cook one packet of instant noodles as they would normally, without the mention of energy use measurements. Three different sized pans and lids were made available so participants could choose the one they preferred. A measurement jug was provided for those who wanted to measure the amount of water to use. The participants could use any hob and also a kettle, and the way they interacted with these appliances was noted and explored. Parallel to this study, a series of experiments took place to simulate the cooking process and understand the appliance behaviours, with the ultimate goal of finding the most efficient way to cook the same food. The following list of energy saving techniques was constructed making sure they could be adhered to safely, using regular equipment and utensils, and without too much effort from the user:

- read and follow the packet instructions

- keep track of time

- measure the amount of water

- use the smallest pan

- use the lid

- choose the smallest hob

- reduce heat when it starts to boil

- turn off the heat 2 or 3 minutes before the end of the cooking time

- do not boil water in the kettle (this will be explained in detail in the Discussion section) 
After developing a set of energy saving techniques for this task, the researcher cooked the same food to determine the minimum amount of electricity necessary to be used. This was used as the baseline against which the energy consumption of the participants performing the same task was compared. The energy efficient cooking techniques identified by the researcher were not communicated to the participants until they had finished cooking but were used during data analysis to evaluate each participant's cooking behaviours.

\section{Results}

Data analysis from the trials showed surprisingly diverse information regarding energy use and also time to complete the task. The performance of the participants was compared with the recommended procedure representing a set of energy saving tech- niques designed by the researcher. These results show that cooking using the energy efficient techniques required 3 times less energy than the average consumed by the participants. When using the energy saving tips during the controlled experiment, only 63 Watts hours (Wh) were used to cook the noodles. The mean value from all the participants was 191.4 Wh. The energy use differed by a factor of 2.8 between participants, with the lowest value $102 \mathrm{Wh}$ and the highest $282 \mathrm{Wh}$ (Figure 1).

Another surprising result is regarding the time to cook the noodles (Figure 2). Even if the package recommends cooking it for 2 to 3 minutes, participants spent much more than that, affecting directly the energy consumption. The mean value from the moment they turned one appliance on until they finished cooking was 9 minutes and 26 seconds.

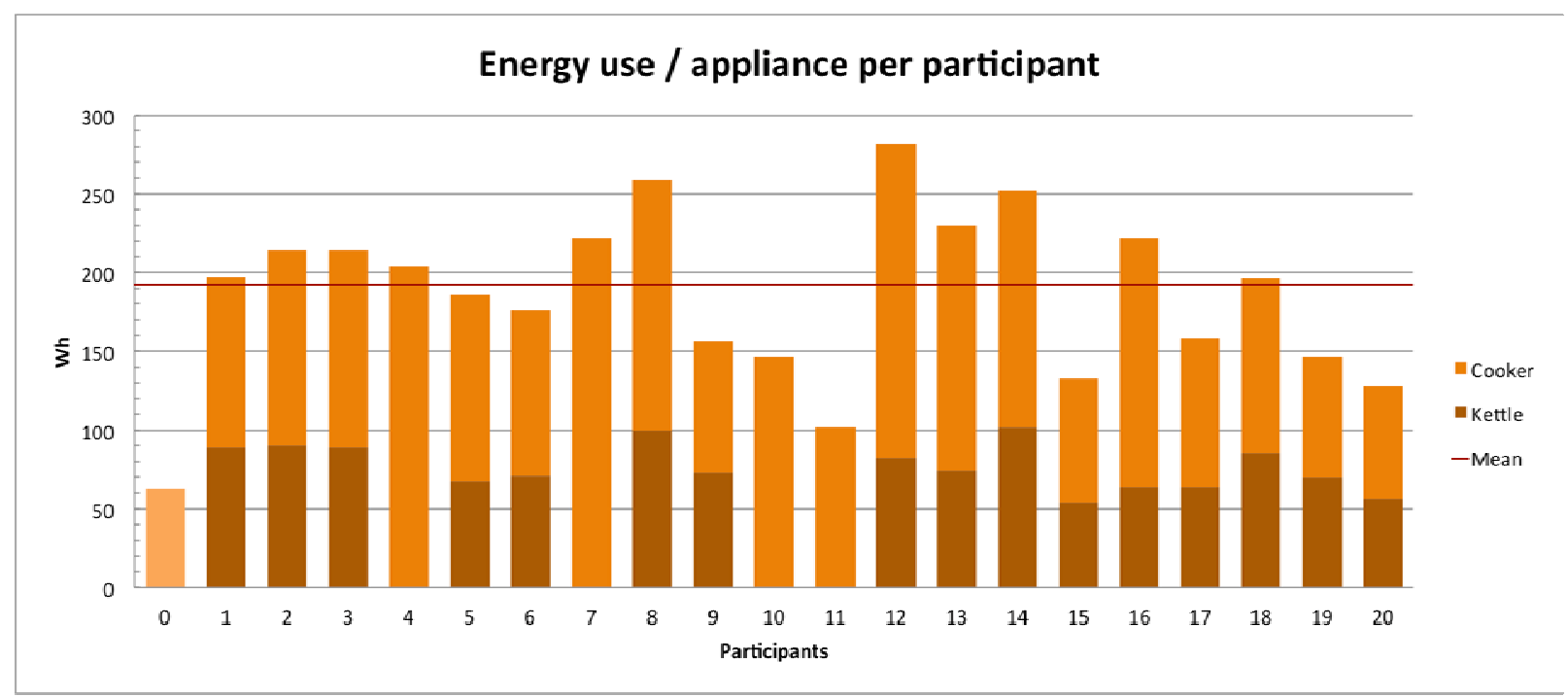

Fig. 1 - Watts hour used combining cooker and kettle (when used). Participant 0 is the researcher applying the energy saving techniques. 


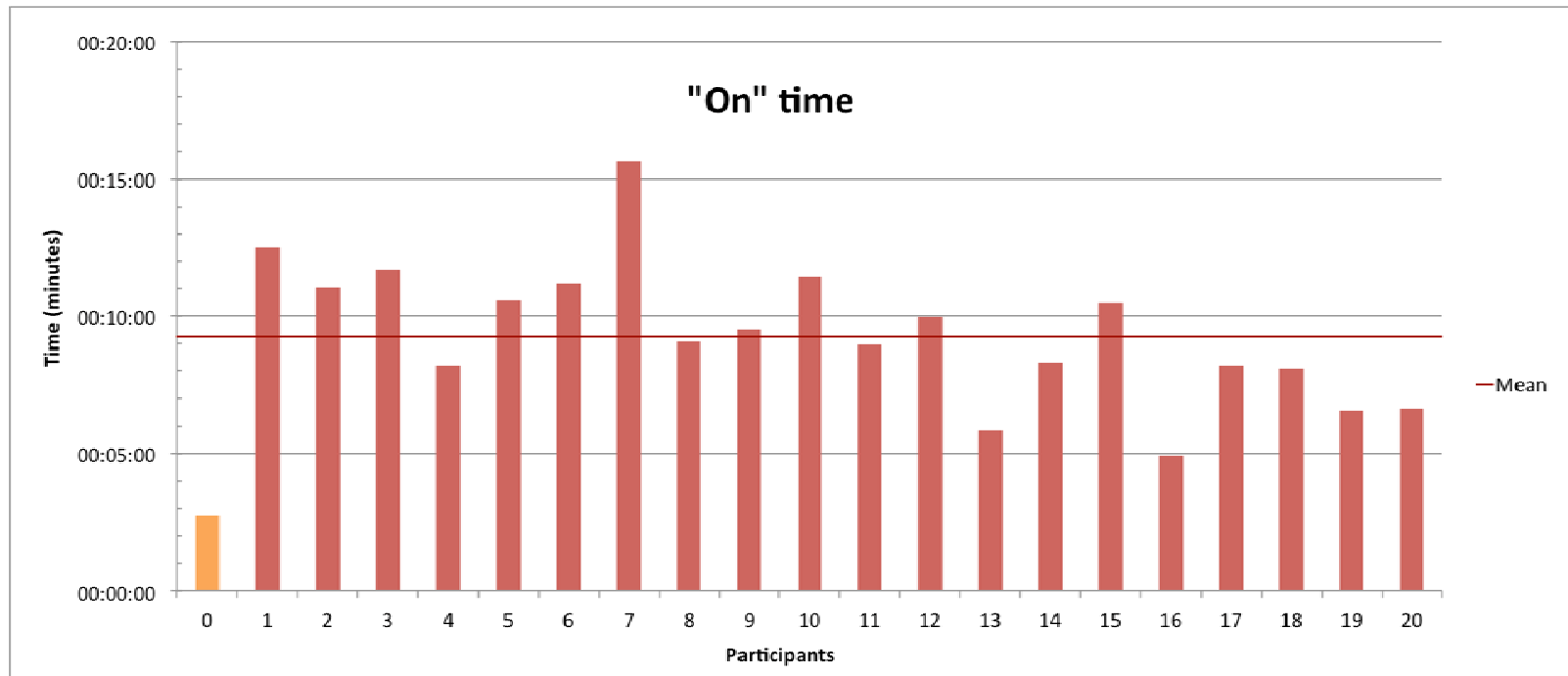

Fig. 2 - Time effectively using energy, from when students turned the appliances on until they switched them off. Participant 0 is the researcher applying the energy saving techniques.

\section{Discussion}

From the user observation study a wider understanding was developed of why participants used more energy and time than needed. Out of the 20 participants, 5 of them did not read the packet instructions at all. Ignoring the instructions meant that they did not pay attention to the amount of water and the time it takes to cook. Even those who read the instructions did not follow all the recommendations. All participants cooked the noodles for longer than recommended on the packet, therefore resulting in extra energy being used. Just 5 participants measured the volume of water to bring to boil, while the others used more water than needed. Overlooking the amount of water substantially increased the overall energy expenditure because more energy is necessary to heat more water. The volume of water also had an indirect influence in the energy consumption as 3 participants kept the noodles boiling for longer, did not use the lid and used high temperature marks in order to make the extra water evaporate.

To speed up the process, 16 of the participants used the kettle first then poured boiling water into the pan. Kettles can provide hot water fairly quickly, but increase the amount of energy necessary to cook noodles. This happens mainly because cooking instant noodles requires just $200 \mathrm{ml}$ of water, and the kettle found in the students' kitchens has a minimum mark of $500 \mathrm{ml}$, resulting in them boiling more water than needed. However, when just hot water is needed, for example when making tea, kettles are still the most efficient way of heating water compared to a pan or a microwave oven [14].

As this experiment involved cooking one single packet of instant noodles, a small pan would be enough to fit the contents. Smaller pans need less energy to heat, but even so 4 participants used the medium sized pan provided instead of the small one. 12 participants used a big hob and a small pan resulting in wasted energy to the air.

By using a lid it is possible to maintain the heat inside and make the process quicker, but just 4 of the students covered their pans. Previous research has shown that simply using lids on saucepans can make the energy consumption three to five times lower [4, cited in 20]. 


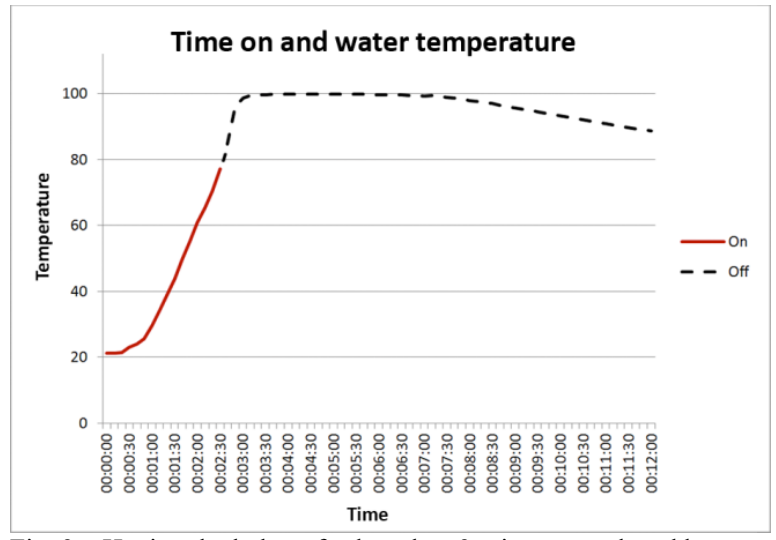

Fig. 3 - Having the hob on for less than 3 minutes produced heat enough to keep the water boiling for about 4 minutes

The hobs used during this experiment consist of a heating element inside a solid metal plate. This hob heats up and then transfers heat to the base of the pan. For this reason, a few minutes are necessary for the metal to heat up and then transfer the heat to the pan, and it also takes a longer time to cool down. Figure 3 Fig. shows the time and the internal temperature of a pan containing $200 \mathrm{ml}$ of water. It was possible to switch the heat source off even before the water had started to boil. 2 minutes and 40 seconds were enough to keep the water boiling for about 4 extra minutes, enough time to complete the task of this study.

Since boiling water stays at a maximum $100^{\circ} \mathrm{C}$ no matter how much energy is put in, the source of heat should be controlled to avoid waste. However, 17 of the participants kept the hob on until the very end of the cooking process. One participant realized that the hob was hotter than needed and decided to start heating another hob to finish the cooking process with less heat.

It was observed that each of the four hobs produces different heat. Two of them have a diameter of about 6 inches and the other two 7 inches. But even with hobs of the same size, the energy consumption (and consequently the heat produced) is different. It happens because the two at the front contain a 'rapid heating element', but the interface or even the user manual does not give any more information about it. Only after analysing the energy consumption per hob and for each mark was it possible to comprehend that the rapid heating feature only occurs when the control is on mark 6. This creates huge differences in heat production that potentially confuse users, with mark 6 using about double the energy of mark 5 for the two

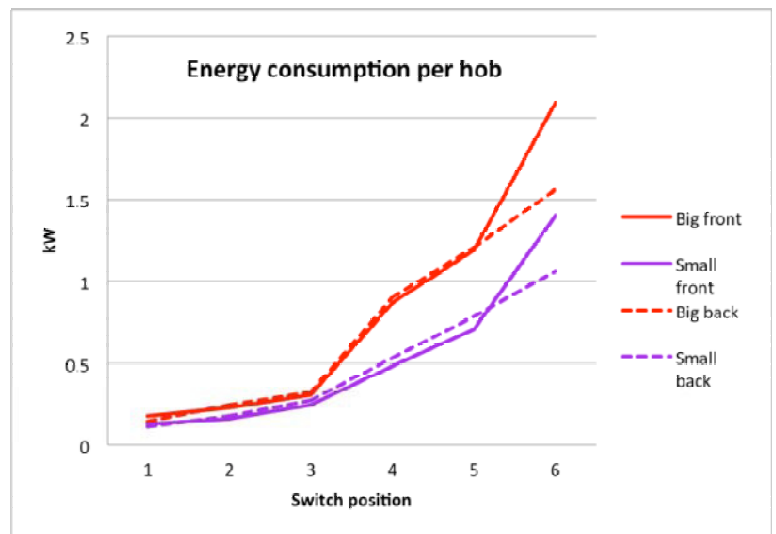

Fig. 4 - Energy use per hob for each control mark

specific hobs at the front (Figure 4). On the other hand, mark 1, 2 and 3 use approximately the same energy across all hobs. Three participants had their hob overheating and, since it stays hot for a long time, had to keep just half of the pan on the hob to limit the heat transfer (Figure 5).

Regarding variation of heating control, 2 participants used only one single heat level during the whole process, 9 participants used 2 different marks to cook, 7 moved the control between 3 marks, and the remaining 2 participants used 4 different marks to cook. This suggest that maybe 6 options are more than needed, especially considering that 3 marks produce about the same heat.

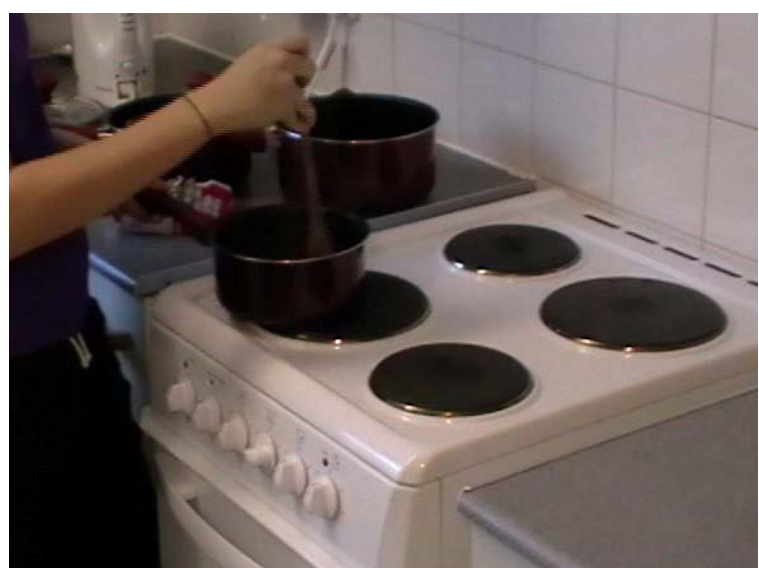

Fig. 5 - Participant trying to minimize the heat transfer due to an overheated hob 


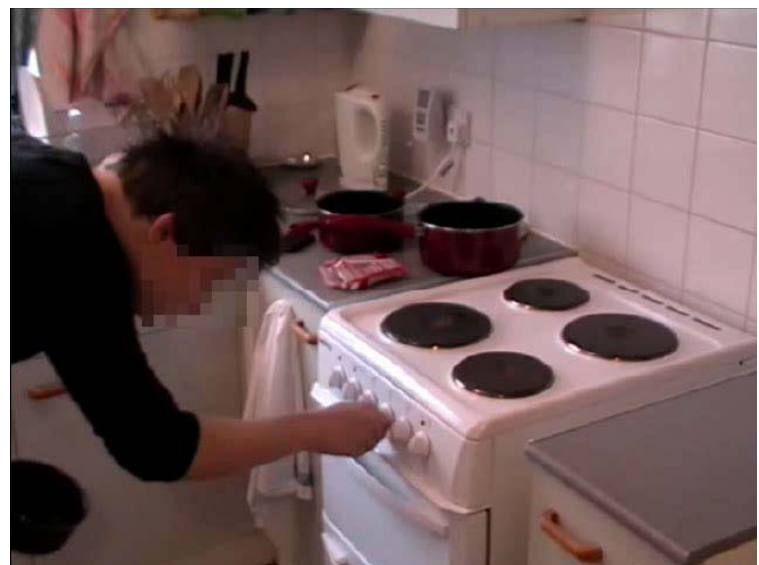

Fig. 6 - One common issue: participants bending down to deal with the controls

The cooker used in this study has four burners arranged in a square but the controls are arranged in a line. Norman [13] comments on this issue: "Most stoves have controls arranged in a line, even though the burners are arranged rectangularly. Controls are not mapped naturally to burners. As a result, you have to learn which control goes with which burner." Studies show that "control configurations should match those of the displays in a one-to-one geometrically corresponding linkage, that is, they should be isomorphic" [5]. Previous research [17] proved that when having controls on the same disposition as the burners, "no subject incurred any errors", whereas if the controls were disposed in a line and the hobs in quadrature, a minimum of $8.6 \%$ of errors occurred, up to $19.2 \%$ depending on the arrangement. In accordance to these studies, participants from this trial also showed difficulty in relating the control with the burner that they were using or having to bend down in order to see closer or from a better angle, to refer to the little diagram and choose the right control (Figure 6).

In addition, the cooker model used has just one 'on' light for all hobs, making it difficult to know which one is being used. This is particularly important with this sort of appliance as there is no visual feedback on the hob comparing to gas cookers where the flame is visible or ceramic and coil hobs that glow red-hot. For that reason, 8 of the participants had to put the hand over the burner to check if it was heating (Figure 7), and one of them ended up using the biggest hob because he selected its control unintentionally in the first place.

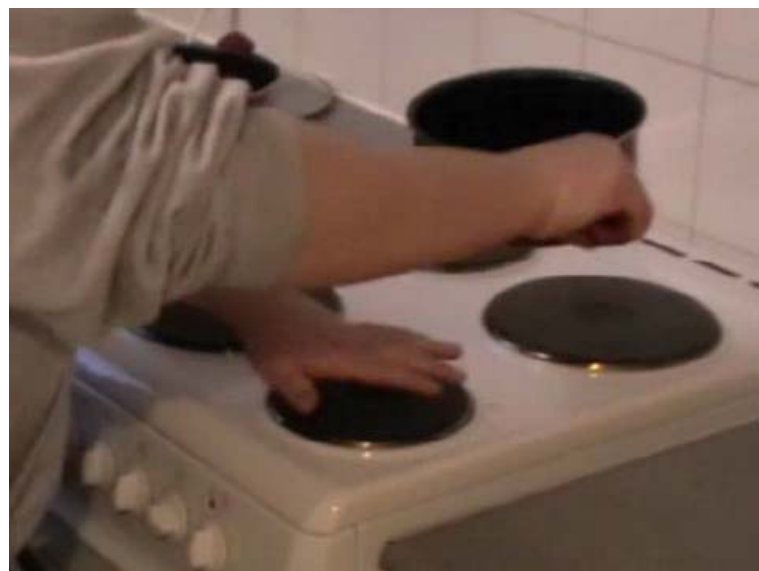

Fig. 7 - 8 participants checked the heat from the hob using their hands

\section{Conclusion}

This research presented the methods and results from a study designed to understand how people interact with electric cookers. A few energy saving techniques specific for cooking instant noodles on a solid plate electric cooker were developed. These techniques worked as a baseline to be compared with people's actual behaviours. The user observation study showed that participants seldom chose to use energy efficient techniques. Consequently, they used 3 times more electricity, on average, than someone following the energy saving tips. The students also demonstrated lack of knowledge about the idiosyncrasies of the cooking appliances available to them. It is understood that participants can provide diverse explanations for their energy use, including personal preferences, habit and convenience [15]. However, human factors issues were found to influence how people use these appliances and consequently resulted in unnecessary energy use. These issues gravitate around usability problems, including poor feedback, the lack of a natural mapping of controls, and differences between how the appliances actually worked and the mental model held by the participant.

The next stage in this research is to use the knowledge of actual cooking behaviours gathered in this study to design an intervention to encourage users to reduce their energy expenditure whilst cooking with regular appliances. This represents a challenge as firstly it is necessary to convince users to change 
their behaviours and adopt the energy saving tips into their everyday cooking behaviours, and secondly to inform people how to overcome the problems found with the available cookers. Based on the results from this study, different behaviour change interventions are being designed. The interaction with the interventions, the acceptance of the methods suggested and its effectiveness will be later evaluated.

This study was conducted within a limited demographic group, using specific appliances and in a reasonably controlled environment. For that reason, further work will be needed if the intention is to gather a broader understanding of user behaviours in different contexts or provide generalizations. The focus of this research is to design and evaluate interventions that motivate people to reduce their energy usage when cooking with existing appliances, often not very efficient. Nevertheless, the results presented here indicate an avenue of research on Design for Sustainable Behaviour [2] and provide useful insights for appliance manufacturers who want to design products that can deliver an improved user experience and at the same time promote energy saving.

\section{Acknowledgements}

The researchers would like to thank participants and staff who made these experiments possible, and also to acknowledge the Loughborough Design School, Loughborough University, United Kingdom, for funding this $\mathrm{PhD}$ program.

\section{References}

[1] Abrahamse, W., Steg, L., Vlek, C., \& Rothengatter, T. (2005). A review of intervention studies aimed at household energy conservation. Journal of Environmental Psychology, 25(3), 273-291.

[2] Bhamra, T., Lilley, D., \& Tang, T. (2011). Design for sustainable behaviour: Using products to change consumer behaviour. The Design Journal, 14(4), 427-445.

[3] Bekker, M. J., Cumming, T. D., Osborne, N. K. P., Bruining, A. M., McClean, J. I., \& Leland, L. S. J. (2010). Encouraging electricity savings in a university residential hall through a combination of feedback, visual prompts, and incentives. Journal of Applied Behavior Analysis, 43(2), 327-331.

[4] Brundrett, G. W., \& Poultney, G. (1979). Saucepan lids: The key to low energy cooking. Journal of Consumer Studies \& Home Economics, 3(3), 195-204.

[5] Chapanis, A., \& Yoblick, D. A. (2001). Another test of sensor lines on control panels. Ergonomics, 44(14), 1302-1311.

[6] Crosbie, T., \& Baker, K. (2010). Energy-efficiency interventions in housing: Learning from the inhabitants. Building Research \& Information, 38(1), 70-79.
[7] Das, T., Subramanian, R., Chakkaravarthi, A., Singh, V., Ali, S. Z., \& Bordoloi, P. K. (2006). Energy conservation in domestic rice cooking. Journal of Food Engineering, 75(2), 156166.

[8] Davis, L. W. (2010). Evaluating the slow adoption of energy efficient investments: Are renters less likely to have energy efficient appliances? NBER - The Design and Implementation of U.S. Climate Policy, 1-16.

[9] Department of Energy and Climate Change. (2010). UK energy in brief. UK: National Statistics.

[10]Directive 2010/30/EU of the European Parliament and of the Council on the indication by labelling and standard product information of the consumption of energy and other resources by energy-related products, 2010.

[11]Hayes, S. C., \& Cone, J. D. (1977). Reducing residential electrical energy use: Payments, information, and feedback. Journal of Applied Behavior Analysis, 10(3), 425-435.

[12] Maguire, M. (2001). Methods to support human-centred design. International Journal Human-Computer Studies, 55(4), 587-634.

[13] Norman, D. A. (2002). The design of everyday things. New York: Basic Books.

[14] Oberascher, C., Stamminger, R., \& Pakula, C. (2011). Energy efficiency in daily food preparation. International Journal of Consumer Studies, 35(2), 201-211.

[15] Oliveira, L., Mitchell, V., \& Badni, K. (2011). Understanding cooking behaviours to design energy saving interventions. Buildings don't use energy, people do? - Research students conference on domestic energy use and $\mathrm{CO} 2$ emissions in existing dwellings, Bath, UK, 1(1), 97-106.

[16]Petersen, J. E., Shunturov, V., Janda, K., Platt, G., \& Weinberger, K. (2007). Dormitory residents reduce electricity consumption when exposed to real-time visual feedback and incentives. International Journal of Sustainability in Higher Education, 8(1), 16-33.

[17] Ray, R., \& Ray, W. (1979). An analysis of domestic cooker control design. Ergonomics, 22(11), 1243-1248.

[18] Sharp, H., Rogers, Y., \& Preece, J. (2007). Interaction design: Beyond human computer interaction (2nd ed.). England: John Wiley \& Sons, 321-348.

[19]Uitdenbogerd, D., Egmond, C., Jonkers, R. and Kok, G., 2007. Energy-related intervention success factors: a literature review. Proceedings of the eceee 2007 Summer Study: Saving EnergyJust Do It, 1(4), 1857-1853.

[20] Wade, J., Hinnells, M., \& Milne, G. (1995). Cooking appliances. Domestic Equipment and Carbon Dioxide Emissions, l(1), 82-94.

[21] Wood, G., \& Newborough, M. (2007). Influencing user behaviour with energy information display systems for intelligent homes. International Journal of Energy Research, 31(1), 5678 . 